\section{Skin Perfusion of Fingers Shows a Negative Correlation with Capillaroscopic Damage in Patients with Systemic Sclerosis}

\section{To the Editor:}

Two variants of laser Doppler monitoring exist to evaluate digital blood flow: laser Doppler imaging (LDI) and laser Doppler flowmetry (LDF). The first technique uses a scanning method with a distant light source and detector, while the second uses optical fibers to carry the light to and from the tissue. As a result, LDF measures the microcirculatory blood flow through a very small volume of tissue, whereas LDI scans a larger tissue area. LDF continuously measures skin blood perfusion; because of the scanning time, LDI cannot measure it continuously ${ }^{1}$.

We address the relationship between digital blood flow and capillaroscopic damage in patients with systemic sclerosis (SSc). Table 1 outlines the main studies.

Using LDI, Correa, et al found lower digital blood flow in 44 patients with SSc compared with healthy controls at baseline and after cold stimulus $^{2}$. No correlation was found between functional and morphological microvascular abnormalities measured by LDI and nailfold capillaroscopy. The authors suggest that it is appropriate to consider LDI and nailfold capillaroscopy as complementary tools for evaluation of different aspects of SSc microangiopathy.

Using LDF, Cutolo, et $a^{3,4}$ demonstrated a significantly lower fingertip blood perfusion in 34 patients with SSc compared with healthy controls. Fingertip blood perfusion correlated negatively with the extent of the nailfold microvascular damage, being lower in patients with SSc with the late nailfold videocapillaroscopy (NVC) pattern of microangiopathy. Interestingly, patients with SSc who showed the late NVC pattern of microangiopathy showed fingertip blood perfusion that was significantly lower than that of patients with the active or early NVC patterns.

Using LDI, Rosato, et $a l^{5}$ demonstrated a significantly lower skin perfusion of hands and fingers in 142 patients with SSc compared with healthy controls. Skin blood perfusion showed a negative correlation with microvascular damage scored according to NVC classification ${ }^{5}$.

In a previous study, we demonstrated that bosentan improved skin perfusion, evaluated by LDI, in patients with SSc, particularly in the skin region distal to the proximal interphalangeal joint and in patients with the early/active capillaroscopic patterns ${ }^{6}$. Additionally, we demonstrated a strong correlation between capillaroscopic patterns and LDI and pulsatility of digital arteries evaluated by photoplethysmography ${ }^{7}$.

Conversely, in 16 patients with SSc, Murray, et $a l^{8}$ demonstrated that nailfold capillaroscopy, LDI, and thermal imaging each independently provide good discrimination between patients with SSc and those with primary Raynaud's phenomenon and healthy controls. LDI and thermal imaging give equivalent information on dynamic changes in the cutaneous microcirculation; however, these correspond only weakly to capillary morphology.

In 127 patients with SSc, Mugii, et al ${ }^{9}$ demonstrated that red blood velocity was significantly associated with NVC findings, including capillary ramification and capillary loss. Patients with the scleroderma active and late NVC pattern showed a lower red blood velocity compared with the scleroderma early pattern.

In 40 patients with $\mathrm{SSc}^{10}$, we demonstrated that thermoregulation of the skin of the fingers, evaluated by LDI after a cold test, is impaired early for the presence of both structural and anatomical changes of microcirculation, while in the dorsum of the hand, thermoregulation is impaired only in advanced stages of SSc microangiopathy.

The term commonly used to describe blood flow measurements by the laser Doppler technique is "flux." Flux has been expressed by perfusion units, which are directly proportional to the product of the mean speed and the concentration of red blood cells. Since red blood velocity is compromised in microvascular disorders, the peripheral blood flow is also steadily reduced.

Skin blood flow depends not only on arterial inflow but also on local factors (blood gases, hormones, temperature). The nutritional skin flow is linked to the integrity of the microvasculature, which consists of a superficial subpapillary plexus and a profound cutaneous plexus. In some areas (e.g., digits, nose, lips, and ears) there are interconnections, often with vascular shunts, between these 2 plexuses. These so-called arteriovenous anastomoses (AVA) enable a fast increase or decrease in blood flow through the skin to regulate the body temperature. The AVA are innervated by the autonomous nervous system ( $a 2 \mathrm{c}$ adrenergic receptors). In the fingers of patients with SSc, the absence of a correlation between skin perfusion and digital arterial flow is due to microvascular damage (giant capillaries, disorganization of the normal capillary array, avascular areas) and AVA shunts. In SSc, microvascular damage is responsible for the

Table 1. Main studies of laser Doppler monitoring and capillaroscopy to evaluate microvascular damage in patients with systemic sclerosis (SSc).

\begin{tabular}{|c|c|c|c|}
\hline Study & No. Patients & Methods & Main Findings \\
\hline Correa $^{2}$ & 44 & LDI and NFC & $\begin{array}{l}\text { LDI and NFC are complementary tools for evaluation of different aspects of SSc } \\
\text { microangiopathy }\end{array}$ \\
\hline Rosato $^{5}$ & 142 & LDI and NVC & $\begin{array}{l}\text { Skin blood perfusion showed a negative correlation with microvascular damage scored } \\
\text { according to NVC classification }\end{array}$ \\
\hline Rosato $^{7}$ & 100 & LDI, NVC, and PPG & $\begin{array}{l}\text { A strong correlation exists between capillaroscopic patterns and digital skin perfusion } \\
\text { and pulsatility of digital arteries }\end{array}$ \\
\hline Murray $^{8}$ & 16 & $\begin{array}{l}\text { LDI, NFC, and } \\
\text { thermal imaging }\end{array}$ & $\begin{array}{l}\text { LDI and thermal imaging give equivalent information on dynamic changes in the } \\
\text { cutaneous microcirculation. However, a combination of all } 3 \text { techniques improves } \\
\text { classification }\end{array}$ \\
\hline Mugii $^{9}$ & 127 & NVC & $\begin{array}{l}\text { Red blood cell velocity was significantly associated with NVC findings. Patients with } \\
\text { the scleroderma active and late NVC pattern showed a lower red blood cell velocity } \\
\text { compared with scleroderma early pattern }\end{array}$ \\
\hline
\end{tabular}

LDI: laser Doppler imaging; LDF: laser Doppler flowmetry; NFC: nailfold capillaroscopy; NVC: nailfold videocapillaroscopy; PPG: photoplethysmography.

Personal non-commercial use only. The Journal of Rheumatology Copyright $\odot$ 2013. All rights reserved. 
baseline digital blood flow reduction, while the AVA may be the main but not exclusive factor in controlling the digital blood flow during cold stimulus. Therefore, local factors are also involved in the regulation of digital blood flow during cold stimulus.

For these reasons, we can suppose that a relationship exists between structural and functional aspects of SSc microvasculature. We can conclude that capillaroscopy represents the best method to analyze microvascular damage in SSc. Therefore, capillaroscopy and LDI show a strong correlation in the definition of structural and functional microvascular damage.

EDOARDO ROSATO, MD; ANTONELLO GIOVANNETTI, MD; SIMONETTA PISARRI, MD; FELICE SALSANO, MD, Sapienza University of Rome, Department of Clinical Medicine, Clinical Immunology Unit - Scleroderma Center, Viale dell'Università 37, 00185 Rome, Italy. Address correspondence to Prof. Salsano;

E-mail: felice.salsano@uniroma1.it

\section{REFERENCES}

1. Stewart J, Kohen A, Brouder D, Rahim F, Adler S, Garrick R, et al. Noninvasive interrogation of microvasculature for signs of endothelial dysfunction in patients with chronic renal failure. Am J Physiol Heart Circ Physiol 2004;287:2687-96.

2. Correa MJ, Andrade LE, Kayser C. Comparison of laser Doppler imaging, fingertip lacticemy test, and nailfold capillaroscopy for assessment of digital microcirculation in systemic sclerosis. Arthritis Res Ther 2010;12:R157.

3. Cutolo M, Ferrone C, Pizzorni C, Soldano S, Seriolo B, Sulli A. Peripheral blood perfusion correlates with microvascular abnormalities in systemic sclerosis: A laser-Doppler and nailfold videocapillaroscopy study. J Rheumatol 2010;37:1174-80.
4. Cutolo M, Sulli A, Pizzorni C, Accardo S. Nailfold videocapillaroscopy assessment of microvascular damage in systemic sclerosis. J Rheumatol 2000;27:155-60.

5. Rosato E, Borghese F, Pisarri S, Salsano F. Laser Doppler perfusion imaging is useful in the study of Raynaud's phenomenon and improves the capillaroscopic diagnosis. J Rheumatol 2009;36:2257-63.

6. Rosato E, Molinaro I, Borghese F, Rossi C, Pisarri S, Salsano F. Bosentan improves skin perfusion of hands in patients with systemic sclerosis with pulmonary arterial hypertension. J Rheumatol 2010;37:2531-9.

7. Rosato E, Molinaro I, Rossi C, Pisarri S, Salsano F. The combination of laser Doppler perfusion imaging and photoplethysmography is useful in the characterization of scleroderma and primary Raynaud's phenomenon. Scand J Rheumatol 2011;40:292-8.

8. Murray AK, Moore TL, Manning JB, Taylor C, Griffiths CE, Herrick AL. Noninvasive imaging techniques in the assessment of scleroderma spectrum disorders. Arthritis Rheum 2009;61:1103-11.

9. Mugii N, Hasegawa M, Hamaguchi Y, Tanaka C, Kaji K, Komura $\mathrm{K}$, et al. Reduced red blood cell velocity in nail-fold capillaries as a sensitive and specific indicator of microcirculation injury in systemic sclerosis. Rheumatology 2009;48:696-703.

10. Rosato E, Rossi C, Molinaro I, Giovannetti A, Pisarri S, Salsano F. Laser Doppler perfusion imaging in systemic sclerosis impaired response to cold stimulation involves digits and hand dorsum. Rheumatology 2011;50:1654-8.

J Rheumatol 2013;40;1; doi:10.3899/jrheum.121042 